\title{
RESEARCH ON THE POSITIONING OF PROTECTION AND UTILIZATION OF HISTORIC DISTRICTS UNDER BIG DATA ANALYSIS
}

\author{
Jingjing Zhang a, Jie Zhang a , Xiaowei Huo a, Weihua Zheng a, Xin Zheng a , Mingming Zhang a \\ a Tsinghua Tongheng Urban Planning and Design Institute, Research Center for Heritage Conservation and Urban- \\ Rural Development, 100085 Beijing, China- \\ icesnow222@126.com,(zhangjie02,huoxiaowei,zhengweihua,zhengxin,zhangmingming)@thupdi.com
}

KEY WORDS: Big Data, Historic District, Protection, Utilization, Positioning

\begin{abstract}
:
Historic districts are a special type of cultural heritage, as living cultural heritage, the utilization and development of historical districts is an inevitable issue. How to accurately position the protection and utilization of districts and achieve its healthy and sustainable development is the key work in the protection of districts. In this paper, the Internet data including Tencent's location big data are employed to study some Chinese historic and cultural streets, establish protection and development index system for historic and cultural streets, carry out in-depth study of ten core indicators, and sum up the positioning and development direction for the protection and use of districts.
\end{abstract}

Historic district, as a special type of cultural heritage, is the birthplace and supporting zone of urban context, and also the place for the daily life of the general public. It boasts profound historic and humanistic background and the characteristics of a living form. As the living cultural heritage, its use and development are necessary, and attention shall also be paid to static protection and dynamic comprehensive management. But judging from the current practice, protection and use of historic districts face a host of challenges. Some districts are devoid of popularity and vitality and become cold galleries. Some districts suffer excessive development for tourism and commercialism, and lose its "original" cultural characteristics. In addition, throngs of tourists exert a negative impact on the life of the local people and the protection of immovable cultural relics. Disorderly business format and increasingly similar landscape go against the presentation of local characteristics.

We should regard historic district as a dynamic urban heritage, and achieve dynamic development and protection in accordance with its inherent development laws and the principle of "step by step" through the "organic update" mode, with emphasis on the continuous comprehensive management of material space environment and cultural society.

Therefore, how to make accurate positioning of the protection and utilization of districts and achieve its healthy and sustainable development is the key work in the protection of districts.

\section{RESEARCH OBJECT AND RESEARCH}

\section{METHODS}

The basic research objects of this study are 50 Chinese historic and cultural streets selected through public appraisal and selection by China Culture Daily Press and the Weekly of China's Cultural Relics over five years from 2009 to 2013 with the approval of the Ministry of Culture and the State Administration of Cultural Heritage of the People's Republic of China. It carried out research on 9 of the 50 historic and cultural streets, including: Yandai Bywayi $\mathrm{n}$ Beijing; Zhongying Street in Shenzhen, Guangdong Province; Qinghefang Ancient Street in Hangzhou, Zhejiang Province; Pingjiang Road in Suzhou, Jiangsu Province; Three Lanes and Seven Alleys in Fuzhou, Fujian Province; Qiao Street, Liping County, Qiandongnan
Autonomous Prefecture, Guizhou Province; Wan'an Ancient Street in Xiuning County, Huangshan City, Anhui Province; Yuliang Street, Shexian County, Huangshan City, Anhui Province; Nanzhao Ancient Street, Weishan Yi and Hui Autonomous County, Dali Bai Autonomous Prefecture, Yunnan Province.

This paper studied the ten core indicators of historic and cultural streets using the internet-based data including Dazhongdianping's POI (Points of Interests) and Tencent location Big Data, as well as five touristoriented platforms including Mafengwo, Ctrip, Qunar, Dazhongdianping and Baidu.

\section{ANALYSIS OF TOP TEN CORE INDICATORS}

The index system draws on the "Disciplines and Guidelines for Social Impact Assessment" 
promulgated by the United States in 1994 and adds the "material space environment" on the basis of the framework of social impact assessment, and forms the five dimensions and index system for the evaluation of historic and cultural streets. Based on the feasibility of the existing data, this study carries out research in ten core indexes.

\subsection{Index1: Close proximity to urban center}

With the distance of historic and cultural streets from the urban center as the horizontal axis, the Baidu search index of historic and cultural streets as the vertical axis, and the circle size representing the population size of the city where historic and cultural streets are located, the historic and cultural streets are divided into three types (Figure 4). Of these, Pingiiang Road, Zhongying Street and so on belong to type one. These are characterized by close proximity to the center of the city and high visibility. Qiao Street, Yuliang Street and so on belong to the type two, which is characterized by location in the center of cities of different scales but with lower visibility. Ancient Nanzhao Ancient Street belongs to type three, which is characterized by its location in the margin of small and medium-sized towns and its low visibility.

\subsection{Index 2: Richness of heritage resources}

The richness of heritage resources mainly refers to the number of units of cultural relics for protection and historic buildings within the district. Through the statistics of the following historic and cultural streets, the richness of heritage resources in different historic and cultural streets varies greatly (Table1).

\begin{tabular}{|l|l|l|l|}
\hline & $\begin{array}{l}\text { Number of } \\
\text { units of } \\
\text { cultural } \\
\text { relics for } \\
\text { protection }\end{array}$ & $\begin{array}{l}\text { Number of } \\
\text { historic } \\
\text { buildings }\end{array}$ & Total \\
\hline $\begin{array}{l}\text { Three Lanes and Seven } \\
\text { Alleys }\end{array}$ & 28 & 131 & 159 \\
\hline Pingjiang Road & 14 & 46 & 60 \\
\hline Yandai Byway & 8 & - & 8 \\
\hline Nanzhao Ancient Street & 25 & - & 25 \\
\hline $\begin{array}{l}\text { Qinghefang Ancient } \\
\text { Street }\end{array}$ & 9 & 7 & 16 \\
\hline Yuliang Street & 14 & - & 14 \\
\hline Wan'an Ancient Street & 14 & 4 & 18 \\
\hline Qiao Street & 2 & - & 2 \\
\hline Zhongying Street & 3 & - & 3 \\
\hline
\end{tabular}

Table 1.Number of units of cultural relics for protection and the number of historic buildings in historic and cultural streets

\subsection{Index 3: Proportion of cultural undertaking and cultural industry facilities}

All facilities are divided into four categories: cultural undertaking, cultural industries, general consumption and others. The facilities which are geared towards the spread of local history and culture and which are mainly non-profit are defined as "cultural undertaking facilities." Profit-oriented facilities which rely on the local historic and cultural resources are defined as "cultural industry facilities." Profit-oriented facilities irrelevant to local historic and cultural characteristics are defined as "general consumption." It can be seen that different historic and cultural streets have different number of cultural undertaking and cultural industry facilities, but the general consumption category is still dominant (Figure 1).

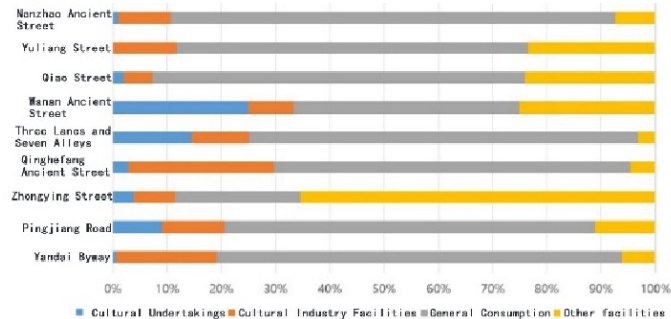

Figure 1 Proportion of cultural undertaking and cultural industry facilities in some historic and cultural streets

\subsection{Index 4: Composition of cultural undertaking} and cultural industry facilities

Cultural undertaking facilities are mainly composed of cultural attractions, museums, and memorials and so on. The composition of the cultural industry facilities is richer, including some established firms, snack stores, teahouses, local dishes, etc. Different historic and cultural streets form their own characteristics in such aspects as established firms, clothing, and folk crafts. Therefore they play a greater role in promoting and spreading the history and culture of districts.

\subsection{Index 5: Distribution characteristics of cultural undertaking and cultural industry facilities}

In the study, the scope of historic buildings for protection and population concentration area is taken as the key scope of research. Through the calculation of cultural facilities in the entire district and the two special types of space, it is found that proportion of cultural facilities in historic buildings is generally higher than that of the overall district, and the proportion of cultural facilities in the populationintensive areas is relatively small, while the proportion of general consumption category and other facilities are relatively high. It goes to show that cultural facilities are attractive points for tourists, but this category does not generate consumption.

\subsection{Index 6: Most widely recognized cultural} undertaking and cultural industry facilities

The recommendation methods of cultural facilities brands at districts are set up based on the principle of public recognition, the diversity of cultural formats and the transmission and spread of district history and culture. The results show that cultural facilities with close ties to local historic and cultural characteristics have a high degree of public recognition, including 
former residences of celebrities, museums, established catering firms and handicraft shops with local characteristics.

\subsection{Index7: Public praise from users}

We analyze the comments of tourists on the five internet platforms based primarily on tourists. First we set up an emotion index ranging from 0 to 1 for historic and cultural streets. A score of 1 indicates full satisfaction of tourists with the overall situation of the district. It can be seen that all the districts have a score above 0.7 , with good overall performance. At the same time, we selected the comments reflecting the negative emotions of tourists and made a summary (Figure 2). We found that of the 24 famous streets for key research, 20 streets are devoid of historic and cultural characteristics, and 18 show signs of overcommercialization.

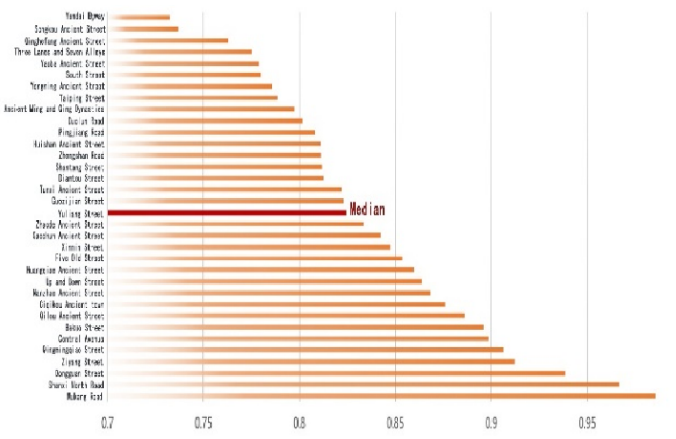

Figure 2 Sentiment index in some historic and cultural streets

\subsection{Index 8: Recognition of characteristics of} famous streets

Some words with highest frequency are selected from the comments of tourists. It is found that the public's cognition of the characteristics of historic and cultural street is usually closely related to its geographical location, historic and cultural connotations, characteristic structures and facilities, space type, architecture, celebrities and food.

\subsection{Index 9: Most popular season for visiting famous} streets

Through the statistics of the number of comments on historic and cultural streets in different seasons, it can be found that some historic and cultural streets show obvious seasonal characteristics due to the local climate and other differences. Qinghefang Ancient Street, Wan'an Ancient Street, Yuliang Street, and Nanzhao Ancient Street are most popular in the spring; Bakuo Street in Lhasa and Five old street in Tianjin are most popular in the summer; Qiao Street and so on are most popular in the autumn; Three Lanes and Seven Alleys is most popular in the winter; Yandai Byway, Zhongying Street, and Pingiiang Road are suitable in all seasons.

\subsection{Index 10: Influence of famous streets}

Based on the data of search clicks from Baidu search platform, an index is obtained from the ratio of the searches using "historic culture + historic and cultural street name" to the searches of "historic culture + city name". An index with a score of more than 1 shows that the street attracts more attention than the city in terms of history and culture. Some of these streets include Three Lanes and Seven Alleys, Zhongshan Road in Xiamen and so on.

\section{RESEARCH ON THE POSITIONING OF PROTECTION AND UTILIZATION OF DISTRICTS}

Through the in-depth analysis of the ten core indicators, combined with the protection status of historic and cultural street and development prospects, it can be found that "Richness of heritage resources" and "influence of famous streets" reflect historical culture situation and advantages of blocks and play a crucial role in its development direction. "close proximity to urban center" embodies the location advantage of blocks and also determines the development direction of blocks to a certain extent. Among indicators related to cultural facilities, though "composition of cultural undertaking and cultural industry facilities", "distribution characteristics of cultural undertaking and cultural industry facilities", and "most widely recognized cultural undertaking and cultural industry facilities" are relatively important indicators, "proportion of cultural undertaking and cultural industry facilities " plays the key role that determines the commercial composition in blocks and potential of cultural industry development. However, "public praise from users", "recognition of characteristics of famous streets", and "Most popular season for visiting famous streets" are three indicators that regard block protection and utilization results as the evaluation basis and won't play a vital role in the development orientation for blocks. We can see the following four indicators play a key role in the development of districts (Table 2).

First, the richness of heritage resources. The more resources it has, the more profound history and culture it contains. Thus it is more conducive to the transmission of history and culture.

Second, the influence of famous streets. The street with an influence index of more than 1 indicates that the street attracts more attention than the city in terms of history and culture. Therefore it is more suitable for it to transmit the history and culture.

Third, the proportion of cultural undertaking and cultural industry facilities. The higher the ratio of cultural undertaking and cultural industry facilities, the more suitable it is for the development of the cultural industries; the lower the proportion of cultural undertaking and cultural industry facilities, the more suitable it is for the continuation of traditional life or 
serving as urban public space.

Fourth, close proximity to the city center. Districts located in urban centers and having high visibility are more suitable for the development of cultural industries, the continuation of traditional life, or serving as urban public space; districts located in the center of cities of different scales but having low visibility are more suitable for the development of the cultural industries or continuation of traditional life; districts located on the edge of small and medium-sized cities and having low visibility are more suitable for the continuation of traditional life.

\begin{tabular}{|c|c|c|c|c|}
\hline $\begin{array}{l}\text { Name of } \\
\text { districts }\end{array}$ & $\begin{array}{l}\text { Richness of } \\
\text { heritage } \\
\text { resources }\end{array}$ & $\begin{array}{l}\text { Influence of } \\
\text { famous } \\
\text { streets }\end{array}$ & $\begin{array}{l}\text { Proportion } \\
\text { of culture } \\
\text { undertaking } \\
\text { and cultural } \\
\text { industry } \\
\text { facilities (\%) }\end{array}$ & $\begin{array}{l}\text { Proximity to } \\
\text { urban center }\end{array}$ \\
\hline Yandai Byway & 8 & $<1$ & 19 & $\begin{array}{l}\text { in the center of } \\
\text { metropolis } \\
\text { high visibility }\end{array}$ \\
\hline $\begin{array}{l}\text { Zhongying } \\
\text { Street }\end{array}$ & 3 & $<1$ & 12 & $\begin{array}{l}\text { in the center of } \\
\text { metropolis } \\
\text { high visibility }\end{array}$ \\
\hline $\begin{array}{l}\text { Qinghefang } \\
\text { Ancient Street }\end{array}$ & 16 & $<1$ & 30 & $\begin{array}{l}\text { in the center of } \\
\text { metropolis } \\
\text { high visibility }\end{array}$ \\
\hline Pingjiang Road & 60 & $>1$ & 21 & $\begin{array}{l}\text { in the center of } \\
\text { metropolis } \\
\text { high visibility }\end{array}$ \\
\hline $\begin{array}{l}\text { Three Lanes } \\
\text { and Seven } \\
\text { Alleys }\end{array}$ & 159 & $>1.5$ & 25 & $\begin{array}{l}\text { in the center of } \\
\text { metropolis } \\
\text { high visibility }\end{array}$ \\
\hline Qiao Street & 2 & $<1$ & 8 & $\begin{array}{l}\text { in the center of } \\
\text { cities of different } \\
\text { sizes } \\
\text { low visibility }\end{array}$ \\
\hline $\begin{array}{l}\text { Wan'an Ancient } \\
\text { Street }\end{array}$ & 18 & $<1$ & 33 & $\begin{array}{l}\text { in the center of } \\
\text { cities of different } \\
\text { sizes } \\
\text { low visibility }\end{array}$ \\
\hline Yuliang Street & 18 & Less than 1 & 12 & $\begin{array}{l}\text { In the center of } \\
\text { cities of different } \\
\text { sizes } \\
\text { low visibility }\end{array}$ \\
\hline $\begin{array}{l}\text { Nanzhao } \\
\text { Ancient Street }\end{array}$ & 25 & Less than 1 & 11 & $\begin{array}{l}\text { on the edge of } \\
\text { small and } \\
\text { medium-sized } \\
\text { towns } \\
\text { low visibility }\end{array}$ \\
\hline
\end{tabular}

Table 2 Four indicators in some historic and cultural streets

Based on the analysis of the indexes and the analysis of the utilization and utilization prospects of nine typical streets, the author sums up the positioning and development direction of protection and utilization of the following four kinds of districts.

First of all, streets that have "influence of famous streets" greater than 1 with "Richness of heritage resources" obviously higher than other streets are defined as "Transmission of history and culture" streets. Secondly, those show "Proportion of culture undertaking and cultural industry facilities" exceeding other blocks can be positioned as "Development of cultural industries" streets. Streets that own a low proportion of cultural undertakings and cultural industry facilities, with development orientation determined by "proximity to urban center", or located at less known urban centers of different scales, or on the edge of medium and small towns with low popularity, can be defined as "Continuation of traditional life" streets. Those located at metropolis centers with high reputation can be regarded as "Urban public space" streets(Table 3 ).

\begin{tabular}{|c|c|c|}
\hline & Characteristic & $\begin{array}{l}\text { Represent } \\
\text { ative } \\
\text { Districts }\end{array}$ \\
\hline $\begin{array}{l}\text { Transmission } \\
\text { of history and } \\
\text { culture }\end{array}$ & $\begin{array}{l}\text { The districts with influence of } \\
\text { famous street greater than } 1 \text { and } \\
\text { having richer heritage than other } \\
\text { districts }\end{array}$ & $\begin{array}{l}\text { Pingjiang } \\
\text { Road, } \\
\text { Three } \\
\text { Lanes and } \\
\text { Seven } \\
\text { Alleys }\end{array}$ \\
\hline $\begin{array}{l}\text { Development } \\
\text { of cultural } \\
\text { industries }\end{array}$ & $\begin{array}{l}\text { Districts with high proportion of } \\
\text { cultural undertaking and cultural } \\
\text { industry facilities }\end{array}$ & $\begin{array}{l}\text { Wanan } \\
\text { Ancient } \\
\text { Street, } \\
\text { Qinghefan } \\
\text { g Ancient } \\
\text { Street, } \\
\text { Yandai } \\
\text { Byway }\end{array}$ \\
\hline $\begin{array}{l}\text { Continuation } \\
\text { of traditional } \\
\text { life }\end{array}$ & $\begin{array}{l}\text { Districts with low proportion of } \\
\text { cultural undertaking and cultural } \\
\text { industry facilities, located in } \\
\text { center of cities of different sizes } \\
\text { but having low visibility or } \\
\text { located on the on the edge of } \\
\text { small and medium-sized towns } \\
\text { and having low visibility }\end{array}$ & $\begin{array}{l}\text { Nanzhao } \\
\text { Ancient } \\
\text { Street, } \\
\text { Yuliang } \\
\text { Street, } \\
\text { Qiao Street }\end{array}$ \\
\hline $\begin{array}{l}\text { Urban public } \\
\text { space }\end{array}$ & $\begin{array}{l}\text { Districts with low proportion of } \\
\text { cultural undertaking and cultural } \\
\text { industry façilities which are } \\
\text { located in the center of } \\
\text { metropoles and have high } \\
\text { visibility }\end{array}$ & $\begin{array}{l}\text { Zhongying } \\
\text { Street }\end{array}$ \\
\hline
\end{tabular}

Table 3 Characteristic and representative districts of four kinds of districts

After an in-depth research on block orientation and development, we put forward following proposals for the development of different types of blocks:

Transmission of history and culture: Carry out strict protection and rational utilization of heritage resources, and maintain the overall style of blocks. Make full use of indoor and outdoor fields of protective architecture to regularly organize various activities that display local cultural features. Strengthen propaganda to make the block become a city name card that authentically reflects local culture.

Development of cultural industries: Increase the proportion of cultural undertakings and cultural industry facilities, control the proportion of general consumer facilities, ensure cultural industry to rely on local historical culture resources and vigorously spread local cultural characteristics.

Continuation of traditional life: Eradicate overcommercialization, and make commercial activities focus on satisfying the life of native dwellers. Strictly 
protect and persist native dwellers' traditional life style. Organize diversified community cultural activities regularly to attract neighborhoods and residents to take an active part in the block conservation and development.

Urban public space: Actively conduct environmental renovation and facility construction, and carry out a variety of cultural activities to make blocks become recreation and activity space for urban residents.

\section{CONCLUSION}

We consider that through the precise Big Data-based analysis, we can identify the problems existing in the protection and development of historic districts, and make accurate positioning of the protection and utilization of blocks, with a view to achieving its healthy and sustainable development and maintaining the continuity of the functions of historic and cultural streets and the transmission of history and culture.

\section{REFERENCES}

Doersch, C., Singh, s., Gupta, A., Sivic,J., and Efros, A.A.,2012, What Makes Paris Look Like Paris? ACM Transactions on Graphics, 31(4), pp.1-9

Quercia, D., Schifanella, R., Aiello, L. M., and Meclean, K., 2015, Smelly Maps:The Digital Life of Urban Smellscapes. Computer Science. 